IP Periodica Polytechnica

Transportation Engineering

47(4), pp. 329-334, 2019

https://doi.org/10.3311/PPtr. 12108

Creative Commons Attribution (i)

\title{
The Visco-Elastic Behavior of PA+PAI Composites with Fiber Glass after UV Degradation
}

\author{
Tatiana Liptáková ${ }^{*}$, Lenka Markovičová ${ }^{1}$ \\ Viera Zatkalíková ${ }^{1}$, Dušan Gaňa ${ }^{1}$ \\ Received 22 July 2017; accepted 19 February 2018
}

RESEARCH ARTICLE

\begin{abstract}
The polymeric composites on the base of the PA+PAI filled by glass fibres are usually used in automotive industry and also exposed to natural atmosphere. The research is focused on resistance study of the mentioned composites in simulated atmospheric conditions. The tested specimens contented 10, 20 and $30 \%$ of the glass fibres and they were exposed in UV box with defined time and intensity of UV radiation and temperature. The mentioned factors have a considerable influence on utility and lifetime of product made of the polymeric composite. The effect of the exposition on the composites behaviour was evaluated microscopically, by rheological measurements and impact tests. By the rheological measurements the changes of visco-elastic parameters (complex viscosity, moduli of elasticity and plasticity) were studied after different times of exposition in the UV box as well as chosen mechanical properties.
\end{abstract}

\section{Keywords}

composite, polymeric matrix, UV radiation, rheology, viscoelastic behaviour, impact strength

\footnotetext{
${ }^{1}$ Department of Materials Engineering,

Faculty of Mechanical Engineering,

University of Žilina,

Univerzitná 8215/1, 01026 Žilina, Slovakia

*Corresponding author, e-mail: tatiana.liptakova@fstroj.uniza.sk
}

\section{Introduction}

The polymer materials combined with reinforcing fibers e.g. glass ones reach the exceptional tensile and compressive strength properties. The polymeric matrix spreads the load applied to the composite between each of the individual fiber and also protects the fibers from damage caused by abrasion and impact. High strengths and stiffness, ease of moulding complex shapes, high environmental resistance all coupled with low densities, make the resultant composite superior to metals for many applications. The composites reinforced by glass fibers (GF) are frequently used in automotive industry because of their physical-chemical and mechanical properties as well as economy. The base of composites can be created by various polymers according to their application. The polymeric bases are sensitive to environmental influences especially where degrade (Peters, 1998; Aird, 2007; Liptáková et al., 2012; Jones, 1994; Shido, 2000). The degradation intensity is depended on the aggressiveness of the environment (strength of sun light, humidity, temperature, etc.). UV radiation in combination with the mentioned factors evokes usually protolysis. The reactions change structure of matrix, visco-elastic properties and thus physical and mechanical properties of products. The changes hence can be studied by rheological measurements of visco-elastic properties of composites (Hussein, 2007; Allen, 2010; Andrady et al., 1994; Hazlinger et al., 2010; Yousif et al., 2015; Gijsman et al., 1999; Mezger, 2006). The goal of the work was to determine the changes of visco-elastic behavior of the PA+PAI composites (with various content of glass fibers), after different times of exposition in UV box as well as their influence on mechanical properties (impact strength, hardness).

\section{Experimental material}

The experimental material is the composite consisting of the PA+PAI (polyamide + polyamidimide) matrix with $10 \%, 20 \%$, $30 \%$ of the glass fibers coded GF 672 with diameter $10 \mu \mathrm{m}$ and length $4 \mathrm{~mm}$. The composites are intended for the interior and exterior details of cars, then it is expected their UV stability. The matrix includes also UV stabilizer. The structures of the tested composites were observed by light microscopy (Zheng 
et al., 2007; Sawyer et al., 2008). In Fig. 1, 2, 3 the surface state of the composites with various content of GF is shown and the distribution of GF in cross section also. Inhomogeneity of the tested composites increases with the amount of GF.
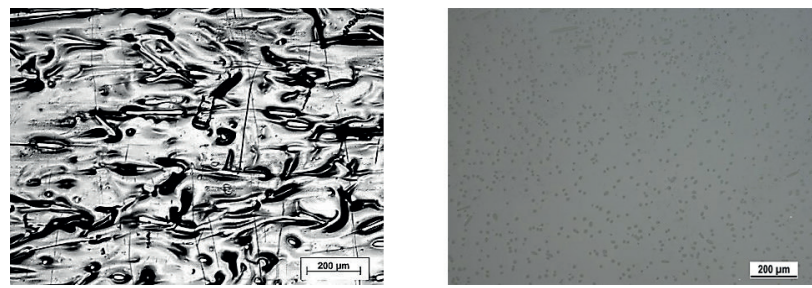

Fig. 1 Surface structure of the tested composites with $10 \%$ of glass fibers content and distribution of GF
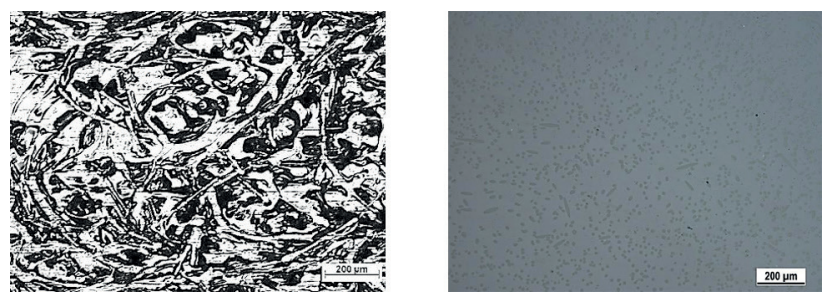

Fig. 2 Surface structure of the tested composites with $20 \%$ of glass fibers content and distribution of GF
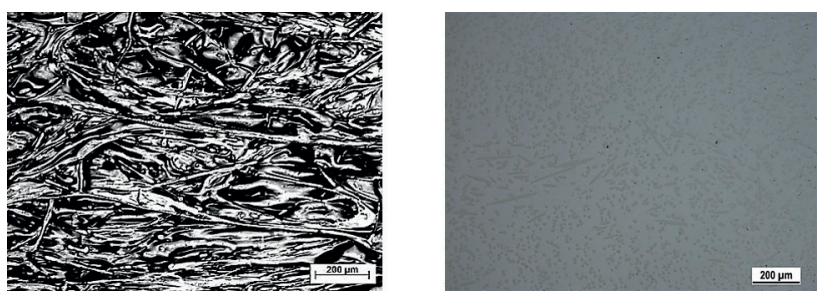

Fig. 3 Surface structure of the tested composites with $30 \%$ of glass fibers content and distribution of GF

The hardness was measured (STN ISO 868 (64 0129) to evaluate the changes of this mechanical property with the increasing fibers (GF) content. The results are in Table 1.

Table 1 Hardness of the tested specimens

\begin{tabular}{lccc}
\hline Content of GF & $10 \% \mathrm{GF}$ & $20 \% \mathrm{GF}$ & $30 \% \mathrm{GF}$ \\
\hline Average value of hardness & 83.44 & 85.74 & 85.94 \\
Standard deviation $[\sigma]$ & 1.312 & 0.233 & 0.598 \\
\hline
\end{tabular}

\section{Experimental results and discussion}

The apparatus for man-made weather ageing ensure continued maintaining of artificial climatic conditions (day and night cycles, changing humidity, drought and wet, etc.). A source of light radiation guarantees a radiant flux of the radiation intensity $550 \mathrm{~W} . \mathrm{m}^{-2}$. The source of light is a xenon arc lamp, but other sources of radiation are allowed too. The device must be equipped with a thermometer built into the black panel, which senses the temperature of the black panel. The black panel temperature of exposure time was selected at $65{ }^{\circ} \mathrm{C}$, the dry phase lasted for 102 minutes and the wet phase for 18 minutes.
If it necessary wetting by distilled or deionised water can be applied. The numbers of man-made climate factors that simultaneously affect the test bars is selected by the test program. Test runs continued for a period fixed in the testing program. The duration of the test was 500, 750 and 1000 hours.

After various time of exposition, surface structure, hardness, impact strength and viscoelastic properties were determined. The most significant changes were recorded after 1000 hours of UV radiation. The changes of the surface after 1000 hours of exposition are in Fig. 4, 5, 6. The evident cracks can be seen in matrix.

That UV radiation is an intense degradation factor affecting the change in the structure of polymers confirmed the experiments. As it can be seen in Fig. 7, 8, 9 degradation of the polymer matrix begins on the interface of matrix and GF. The biggest changes in the polymer structure were observed in the material with $10 \%$ glass fiber content because of the largest area of matrix exposed to radiation. Degradation is gradually spread from the material surface to the center. The UV radiation causing rupture initiated away from glass fibers. Prolonged exposure to UV radiation has been associated with

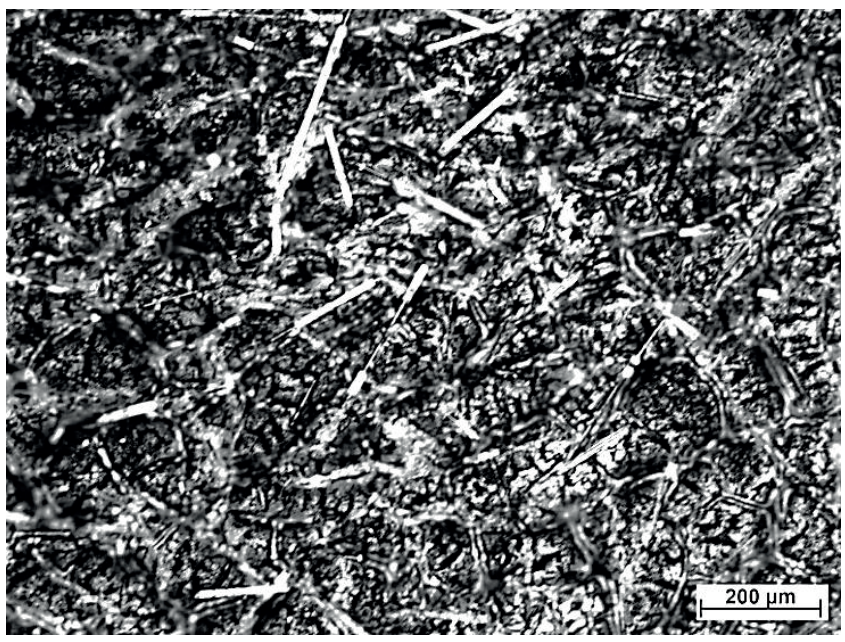

Fig. 4 Surface structure of the tested composites with $10 \%$, of glass fibers content after 1000 hours exposition in UV box

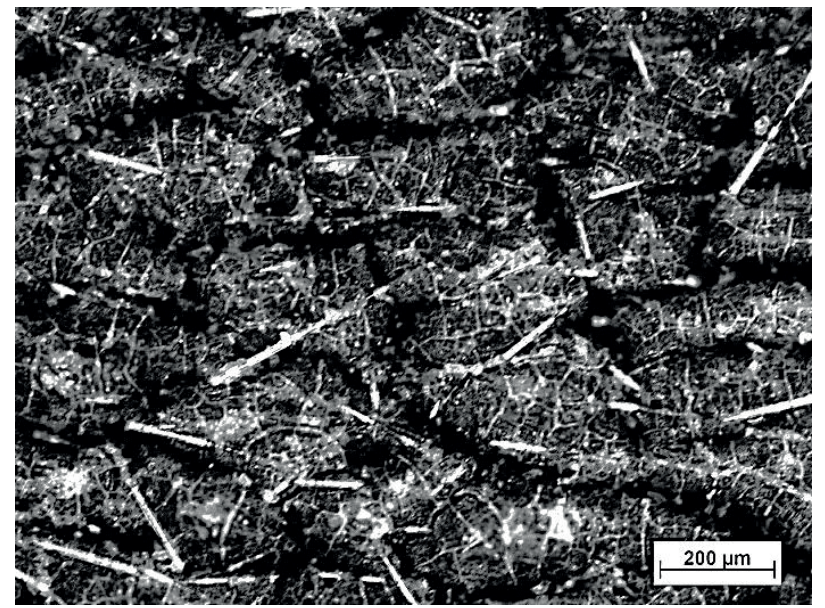

Fig. 5 Surface structure of the tested composites with $20 \%$ of glass fibers content after 1000 hours exposition in UV box 


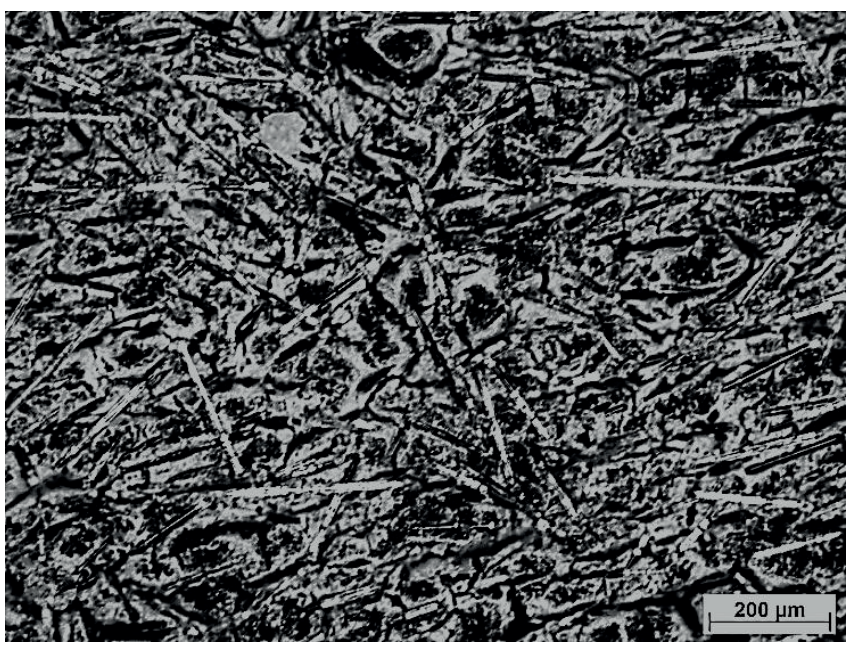

Fig. 6 Surface structure of the tested composites with $30 \%$ of glass fibers content after 1000 hours exposition in UV box

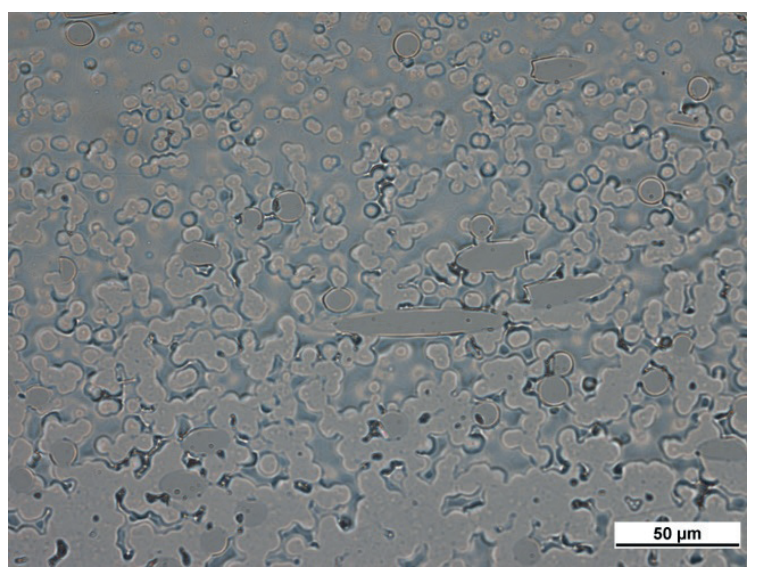

Fig. 7 Surface structure of the tested composites with $10 \%$ of glass fibers content after 1000 hours exposition in UV box

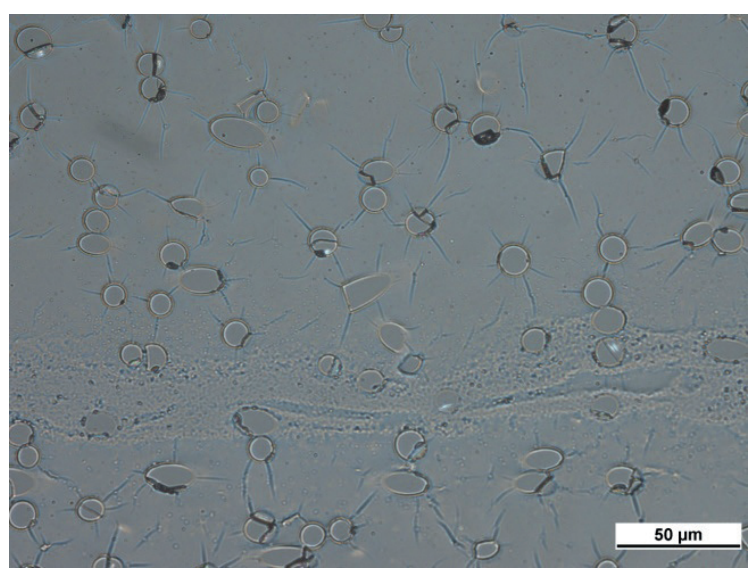

Fig. 8 Surface structure of the tested composites with $20 \%$ of glass fibers content after 1000 hours exposition in UV box

cracks spread and their depth. The polymer matrix-fiber interface exhibits low adhesion, which is needed in the future to support by the addition of the more efficient adhesive agent.

The cracks are started from the matrix-fiber interface were the changes of visco-elastic properties evoke the large stress. In the composite with $30 \%$ of GF the cracks density is most

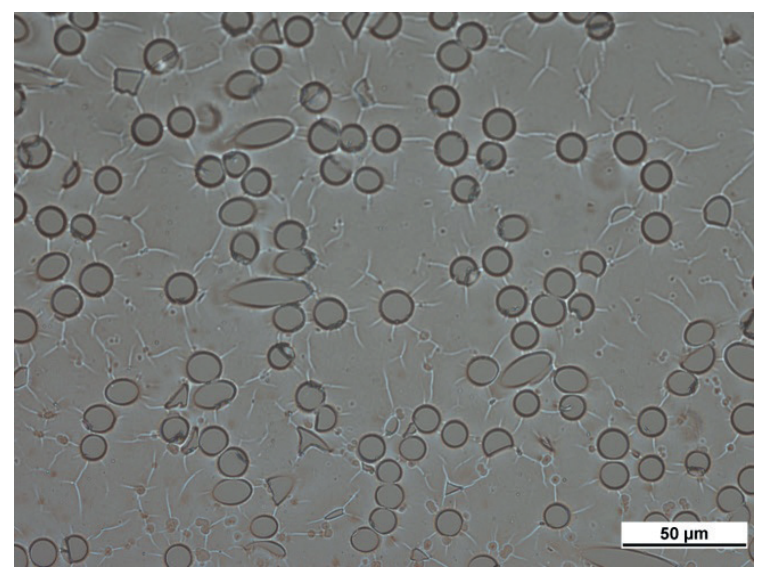

Fig. 9 Surface structure of the tested composites with $30 \%$ of glass fibers content after 1000 hours exposition in UV box

massive. This fact is reflected on the measured rheological parameters and impact strength.

The hardness (HSD) of the composite depends mainly on the content and distribution of the glass fibers in the polymer matrix. After 500 and 750 hours of UV exposition the HSD changes are negligible, slightly increased HSD after 1000 hours of UV irradiation. It may be as a result of the partial crosslinking of the polymer matrix and changes in GF distribution (Table 2).

Table 2 Hardness of the tested specimens after 1000 hours of UV radiation

\begin{tabular}{cccc}
\hline Content of GF & $10 \% \mathrm{GF}$ & $20 \% \mathrm{GF}$ & $30 \% \mathrm{GF}$ \\
\hline Average value of hardness & 84.24 & 85.24 & 86.06 \\
Standard deviation $[\sigma]$ & 0.51 & 0.75 & 0.81 \\
\hline
\end{tabular}

The rheological measurements were carried out on the Physica Rheometer MCR 301 with a convective heating device CTD 450. By the method DMTA (Dynamic Mechanical Thermal Analysis) (Mezger, 2006; Vojsovičová et al., 2011; Wollny, 2006; Lelovics and Liptáková, 2010) the parameters were evaluated:

$\mathrm{G}^{\prime \prime}(\mathrm{Pa})$ - loss modulus is a measure of deformation energy used up by sample during shear process and shows irreversible deformation energy, presents the viscous behaviour of tested material. $\mathrm{G}^{\prime}(\mathrm{Pa})$ - storage modulus is a measure of the deformation energy stored by samples during the shear process is showing reversible deformation behaviour, represent elastic behaviour of tested material. The complex modulus is expressed by the equation (1):

$$
\left|G^{*}\right|=\sqrt{\left(G^{\prime}\right)^{2}+\left(G^{\prime \prime}\right)^{2}} .
$$

Tan $\delta$ - damping factor (Eq. (2)) represents ratio of the used up and accumulated deformation energy (Andrady et al., 1994; Hazlinger et al., 2010; Yousif et al., 2015; Gijsman et al., 1999; Mezger, 2006).

$$
\tan \delta=G^{\prime \prime} / G^{\prime} .
$$

$\eta^{*}$ - complex viscosity (Eq. (3)) represents ratio of $\eta^{\prime}$ expressed elastic behavior of polymeric and $\eta$ " viscous one (Yousif et al., 2015; Gijsman et al., 1999): 


$$
\left|\eta^{*}\right|=\sqrt{\left(\eta^{\prime}\right)^{2}+\left(\eta^{\prime \prime}\right)^{2}}
$$

The measurements were made on the specimens with dimensions $40 \mathrm{~mm}$ length, $8 \mathrm{~mm}$ and $4 \mathrm{~mm}$ thickness, angle deformation $\gamma$ was $0.01 \%$ at oscillation with frequency $1 \mathrm{~Hz}$ and heating rate $2{ }^{\circ} \mathrm{C} \cdot \mathrm{min}^{-1}$ (ISO 6721-10 (ISO 1999). Temperature range was from $25^{\circ} \mathrm{C}$ to $250{ }^{\circ} \mathrm{C}$.

In Fig. 10 the complex viscosities of the experimental composites in initial state and in Fig. 11 after 1000 hours of exposition are compared.

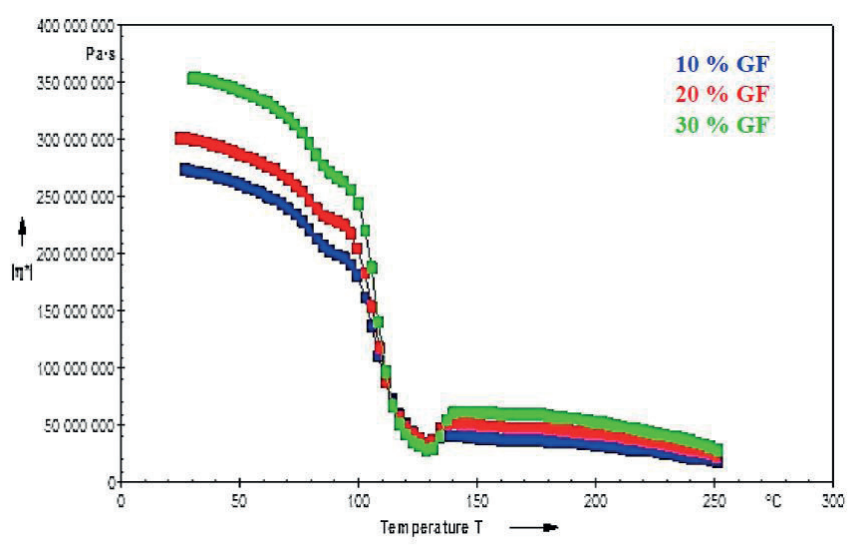

Fig. 10 Complex viscosities of the tested composites (initial state) in dependence on temperature

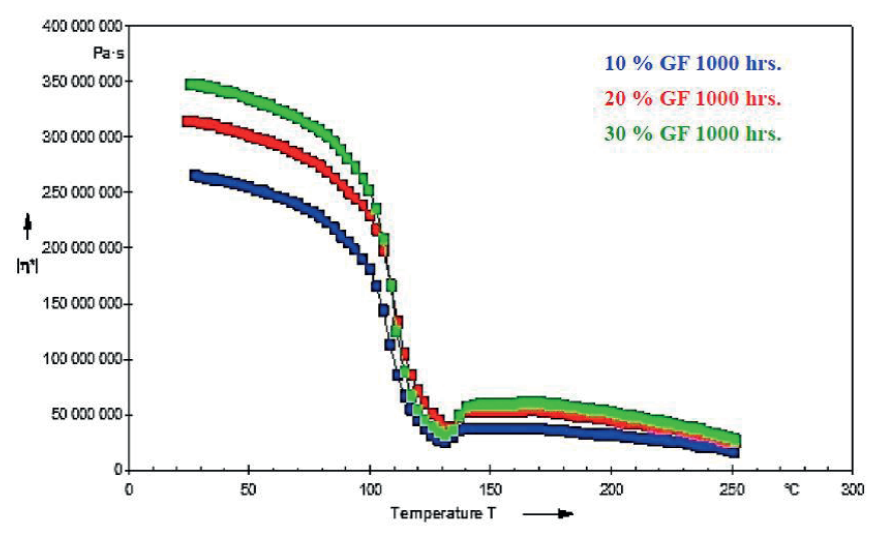

Fig. 11 Complex viscosities of the tested composites in dependence on temperature after 1000 hour lasted exposition

Viscosity of the tested composites grows with amount of the GF. After radiation of 500 and 750 hours the changes of complex viscosity were low of all specimens (Fig. 12,13) but after 1000 hours drop of viscosity was evident especially in specimens with $10 \%$ of GF. Changes can be caused by more intensive degradation of matrix by chain branching, transformation of crystallinity, removing of hydrogen bridges (Gijsman et al., 1999; Carraher, 2007; Achhammer et al., 1951). It can evoke arrangement of GF, their moving in matrix and then visco-elastic properties too. From the course of complex viscosity curves effect of temperature is evident and critical one

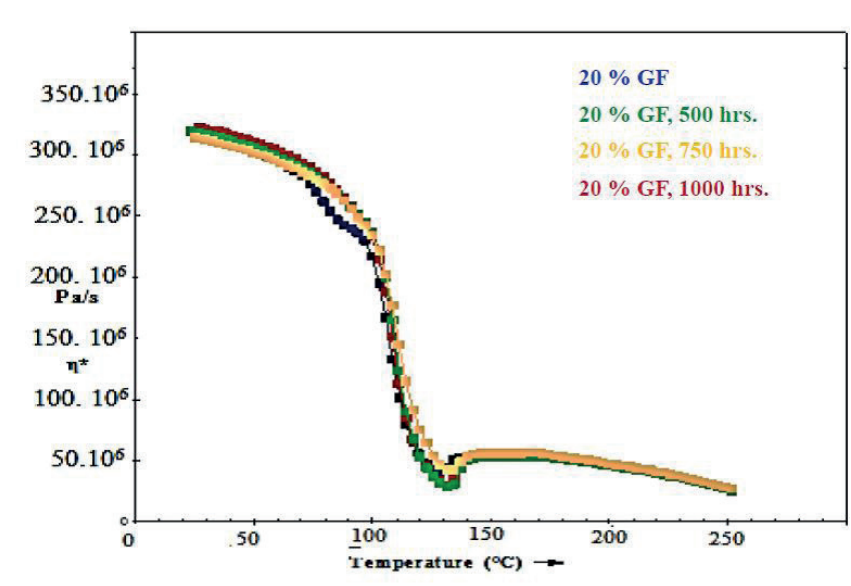

Fig. 12 Comparison of changes of complex viscosities of the composites with $20 \%$ of GF after exposition

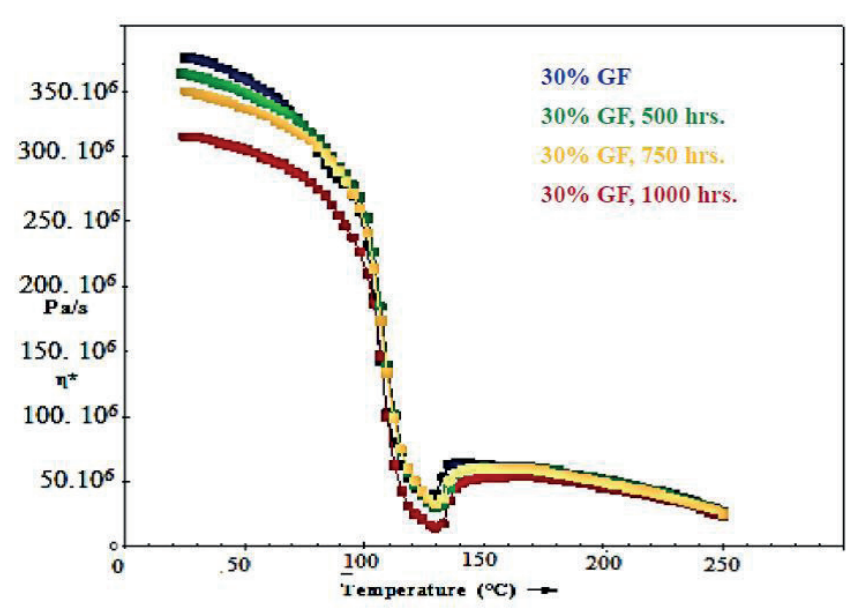

Fig. 13 Comparison of changes of complex viscosities of the composites with $30 \%$ of GF after exposition

when the composites reach softening. This temperature is by content of the GF a little moved to higher values and radiation it also increases.

The effect of exposition of the PA+PAI composite in simulated atmospheric conditions with intensive radiation was observed evidently also on damping factor presenting by the ratio of loss and storage moduli.

Differences between visco-elastic properties of the specimens in the initial state are higher than after the exposition (Fig. 15). It means increasing of the elastic properties and drop of the plastic ones. In Fig. 14 and Fig. 15 the changes of initial state and after 1000 hours of exposition are compared. The composites become after UV radiation more brittle, include more cracks and also the fibres are liberated from their positions. It modifies their mechanical properties and enhances inhomogeneity.

The effect of the UV-degradation was observed on the results of the impact test published in Table 3. It can be seen the results are in the accordance with the results of the carried out rheological tests as well as microscopic documentation. 


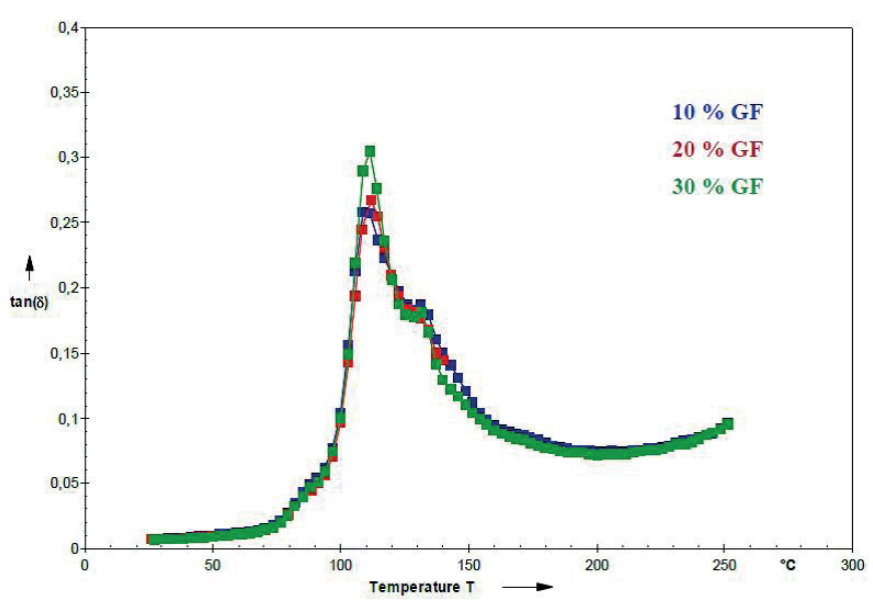

Fig. 14 Internal damping of the composites (initial state) with different content of the GF

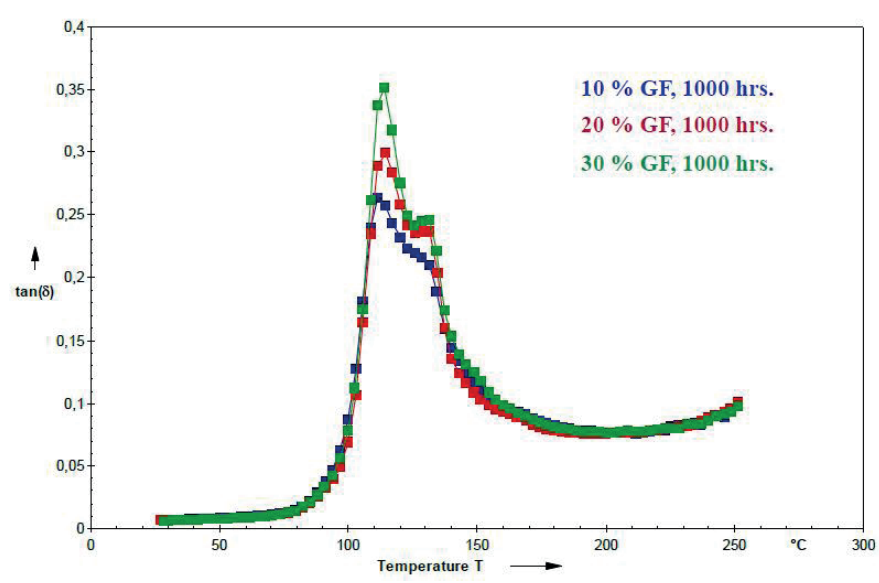

Fig. 15 Internal damping of the composites with different content of the GF after UV exposition

Table 3 Changing the Dynstat impact strength before and after $1000 \mathrm{hrs}$.

\begin{tabular}{ccc}
\multicolumn{3}{c}{ UV radiation } \\
\hline \multirow{2}{*}{ Content of GF } & Impact strength Dynstat $\left(\mathrm{kJ} . \mathrm{m}^{-2}\right)$ \\
& $0 \mathrm{UV}$ & $1000 \mathrm{UV}$ \\
\hline $10 \%$ & 26.4 & 19.8 \\
$20 \%$ & 53.3 & 21.8 \\
$30 \%$ & 59.9 & 25.5 \\
\hline
\end{tabular}

\section{Conclusion}

With increasing of the GF content hardness and viscosity of composites grows. This fact is related to different mechanical properties of GF distributed in matrix.

The simulated atmospheric condition with an intensive UV radiation caused matrix degradation and it affects not only viscoelastic behavior of composites but distribution of GF. It is supported by the fact that alternation of mechanical and visco-elastic properties is more obvious in composites with higher content of GF.

After UV degradation the generated cracks are spread from the matrix-fiber interface, their amount growth with the content of GF.
The changes by the effect of environment with present UV radiation reduce products quality and life time. The possibility of reducing degradation processes is in using of effective UV stabilizers.

\section{Acknowledgement}

The project presented in this article is supported by European regional development fund and Slovak state budget by the project ITMS 26220220121.

\section{References}

Achhammer, B. G., Reinhart, F. W., Kline, G. M. (1951). Mechanism of the Degradation of Polyamides. Journal of Research of the National Bureau of Standars. 46(5), pp. 391-421.

Aird, F. (2007). Fiberglass and composite materials. Springer, New York, USA. pp. 857-866.

Allen, N. S. (2010). Photochemistry and Photophysics of Polymer Materials. Wiley, New Jersey, USA.

Andrady, A. L., Amin, M. B., Hamid, S. H., Hu, X., Torikai, A. (1994). Effects of Increased Solar Ultraviolet Radiation on Materials. In: Environmental Effects of Ozone Depletion: 1994 Assessment. United Nations Environment Programme (UNEP). [Online] Available from: http://sedac.ciesin. org/ozone/UNEP/chap7.html [Accessed 16th December 2016]

Carraher, C. E., Jr. (2007). Introduction to Polymer Chemistry. CRC Press, Taylor \& Francis Group, Boca Raton, Florida, USA.

Gijsman, P., Meijers, G., Vitarelli, G. (1999). Comparison of the UV-degradation chemistry of polypropylene, polyethylene, polyamide 6 and polybutylene terephthalate. Polymer Degradation and Stability. 65(3), pp. 433-441.

Hazlinger, M., Moravčík, R., Čaplovič, L. (2010). Degradačné procesy a predikcia životnosti materiálov. (Degradation Processes and Prediction of Materials Life-time.) STU: Slovak University of Technology in Bratislava, Slovakia. (in Slovak)

Hussein, I. A. (2007). Rheological investigation of the influence of molecular structure on natural and accelerated UV degradation of linear low density polyethylene. Polymer Degradation and Stability. 92(11), pp. 2026-2032.

Jones, F. R. (1994). Handbook of Polymer-Fibres Composites. Longman Publishing Group, New York, USA.

Lelovics, H., Liptáková, T. (2010). Rheological properties of acrylic bone cement SmartSet巴HV. Komunikacie. 12(4), pp. 85-89.

Liptáková, T., Alexy, P., Gondár, E., Khunová, V. (2012). Polymérne konštrukčné materiály. (Polymeric construction materials.) EDIS: Publishing Institution of Zilina University, Zilina, Slovakia. (in Slovak)

Mezger, T. G. (2006). The Rheology Handbook. 2nd edition. Vincentz Network, Hannover, Germany.

Peters, S. T. (1998). Handbook of composites. Chapman and Hall, London, UK.

Sawyer, L. C., Grubb, D. T., Meyers, G. F. (2008). Polymer Microscopy. 3rd edition. Springer, New York, USA. 540.

Shido, A. (2000). Encyklopedia of Comprehensive Composite Materials. Vol. 1, Fiber Reinforcements and General Theory of Composites, 1,

Vojsovičová, M., Liptáková, T., Zatkalíková, V. (2011). Rheological characteristics of thermoplastic polymers after degradation. In: Communications, Scientific Letters of the University of Zilina. 13, EDIS: Publishing Institution of Zilina University, Zilina, Slovakia. pp. 32-35.

Wollny, K. (2006). DMTA investigation of a polymethyl methacrylate (PMMA) over a temperature range of $-150{ }^{\circ} \mathrm{C}$ to $160{ }^{\circ} \mathrm{C}$. Application Note of Physica Rheometers.

Yousif, E., El-Hiti, G. A., Hussain, Z., Altaie, A. (2015). Viscoelastic, Spectroscopic and Microscopic Study of the Photo Irradiation Effect on the 
Stability of PVC in the Presence of Sulfamethoxazole Shiff's Bases. Polymers. 7, pp. 2190-2204.

Zheng, Q., Min, Z., Mao, P., Lie, S., Yurun, F. (2007). Rheological study of microstructures and properties for polymeric materials. Frontiers of $\mathrm{Ma}$ terial Science in China. 1(1), pp. 1-6. 